\title{
44620 - EFFECT OF CPB AND ANEMIA ON RAT RENAL TISSUE PO2 AND ENOS EXPRESSION
}

\author{
Peter Darby, St. Michael's Hospital, University of Toronto, Toronto, ON, Canada; \\ Francoise Briet, St Michael's Hospital, University of Toronto; \\ Greg Hare, St Michael's Hospital, University of Toronto; \\ A Harrington, St Michael's Hospital, University of Toronto; \\ CD Mazer, St Michael's Hospital, University of Toronto;
}

INTRODUCTION: Renal failure is a serious complication of cardiopulmonary bypass (CPB) surgery, with significant morbidity and mortality ${ }^{1}$. Anemia is an independent predictor of RF following $\mathrm{CPB}^{2}$, possibly due to inadequate renal oxygen delivery. We investigated the effects of $\mathrm{CPB}$ and anemia on renal cortical and medullary tissue oxygen tension (pO2), blood flow (RBF) and eNOS protein expression.

METHODS: With Animal Care Committee approval, anesthetized rats (ketamine, isoflurane, fentanyl, propofol) underwent $1 \mathrm{~h}$ of normothermic CPB. Two groups of animals were studied in which the target hemoglobin concentration $(\mathrm{Hb})$ was either $100 \mathrm{~g} / \mathrm{L}(\mathrm{CPB})$ or $65 \mathrm{~g} / \mathrm{L}(\mathrm{CPB}-$ Anemia). Combined oxygen sensing microelectrodes and laser Doppler flow probes (Oxford Optronix) were placed in the renal cortex and medulla in each rat for simultaneous measurement of $\mathrm{RBF}$ and $\mathrm{pO} 2$. Absolute $\mathrm{pO} 2$ values $(\mathrm{mmHg})$ or relative increases in $\mathrm{RBF}(\%)$ were measured. Different groups of rats were sacrificed immediately after bypass, or 6h post-bypass, to assess renal eNOS expression by immunohistochemistry. Statistical analysis was performed using ANOVA on ranks and Mann-Whitney rank sum tests.

RESULTS: There were no differences in physiologic variables between groups at baseline. $\mathrm{Hb}$ decreased from a baseline of $116 \pm 17$ to $97 \pm 7$ in the CPB group, and further decreased to $64 \pm 7$ in the CPB-Anemia group ( $\mathrm{p}<0.05)$. Basal renal cortical pO2 values $(16.1 \pm 9.2 \mathrm{mmHg})$ were higher than medullary $\mathrm{pO} 2$ values $(4.9 \pm 3.0 \mathrm{mmHg}, \mathrm{n}=8, \mathrm{p}<0.001)$. Renal cortical $\mathrm{pO} 2$ decreased during CPB (7.0 $\pm 3.6, n=4)$ and CPB-Anemia $(6.9 \pm 5.2, n=4)(p=0.031)$. Renal medullary pO2 was decreased during CPB (2.7 $\pm 1.7, n=4)$ and further decreased with CPB-Anemia $(1.2 \pm 0.9, n=4)$ $(\mathrm{p}=0.015)$. Renal cortical and medullary blood flow did not change significantly during CPB but increased during CPB-Anemia $(151 \pm 50 \%$ and $221 \pm 92 \%, \mathrm{n}=8, \mathrm{p}<0.05)$. Immunohistochemical analysis demonstrated eNOS staining in renal blood vessels immediately after CPB and increased eNOS staining 6 hours post-CPB in both groups $(n=4)$.

DISCUSSION: In this model, tissue pO2 was significantly lower in renal medulla compared with cortex prior to $\mathrm{CPB}$. During $\mathrm{CPB}, \mathrm{pO} 2$ was reduced in both renal cortex and medulla with maintained RBF. CPB with anemia caused a further reduction in renal medullary pO2, despite a significant increase in medullary blood flow. These data suggest that the renal medulla is more susceptible to hypoxic injury during CPB with anemia. Increased renal eNOS expression may play a role in mediating $\mathrm{RBF}$ during $\mathrm{CPB}$ and anemia.

REFERENCES:

1. Br J Anesth 2005 95:20-32 
2. J Thorac Cardiovasc Surg 2005 129:391-400 